\title{
Partitioning of Cephalexin in Ionic Liquid Aqueous Two-Phase System Composed of 1-Butyl-3-Methylimidazolium Tetrafluoroborate and $\mathrm{ZnSO}_{4}$
}

\author{
Yan Fang Li, ${ }^{1}$ Juan Han, ${ }^{1}$ Yun Wang, ${ }^{1}$ Jing Jing $\mathrm{Ma}^{2}{ }^{2}$ and Yong Sheng Yan $^{1,3}$ \\ ${ }^{1}$ School of Chemistry and Chemical Engineering, Jiangsu University, Zhenjiang 212013, China \\ ${ }^{2}$ School of Biological and Chemical Engineering, Jiangsu University of Science and Technology, Zhenjiang 212003, China \\ ${ }^{3}$ State Key Laboratory of Natural and Biomimetic Drugs, Peking University, Beijing 100191, China
}

Correspondence should be addressed to Yong Sheng Yan; yys@ujs.edu.cn

Received 26 June 2012; Accepted 5 October 2012

Academic Editor: A. Irabien

Copyright (c) 2013 Yan Fang Li et al. This is an open access article distributed under the Creative Commons Attribution License, which permits unrestricted use, distribution, and reproduction in any medium, provided the original work is properly cited.

Ionic liquid aqueous two-phase system (ILATPS) was applied in the extraction and separation of hydrosoluble antibiotics. The partitioning behavior of cephalexin $(\mathrm{CEX})$ in 1-butyl-3-methylimidazolium tetrafluoroborate $\left([\mathrm{Bmim}] \mathrm{BF}_{4}\right)-\mathrm{ZnSO}_{4}$ aqueous twophase system was studied by the partitioning parameter of the extraction efficiency. The effect of the volume of $\left[\mathrm{Bmim}^{\mathrm{B}} \mathrm{BF}_{4}\right.$, the concentration of $\mathrm{ZnSO}_{4}$, temperature, $\mathrm{pH}$, and the volume of $\mathrm{ZnSO}_{4}$ solution was discussed concretely. When the volume of [Bmim] $\mathrm{BF}_{4}$ was $2 \mathrm{~mL}$ and the concentration of $\mathrm{ZnSO}_{4}$ was $35 \%$, the extraction efficiency of CEX could reach $92.64 \% \mathrm{with} \mathrm{pH}$ unadjusted. The effect of the volume of $[\mathrm{Bmim}] \mathrm{BF}_{4}$ on the extraction efficiency was higher than that of the concentration of $\mathrm{ZnSO}_{4}$. The temperature influenced not only the formation of aqueous two-phase system but also the extraction efficiency of CEX. The target was found to be preferentially extracted to the $[\mathrm{Bmim}] \mathrm{BF}_{4}$-rich phase at the $\mathrm{pH}$ below 4.3 . The partition of CEX to the top phase was enhanced by increasing the volume of $\left[\mathrm{Bmim}_{3} \mathrm{BF}_{4}\right.$, the concentration of $\mathrm{ZnSO}_{4}$, and temperature; however, the partition of CEX to the top phase increased by decreasing the $\mathrm{pH}$.

\section{Introduction}

For its gentle conditions, high biocompatibility and capacity and high extraction yield, aqueous two-phase extraction (ATPE), a novel liquid-liquid extraction technique, has been widely applied in the separation, concentration, and purification of biomolecules, such as proteins, nucleic acids, enzymes, antibodies, and antibiotics [1-6]. Aqueous two-phase system (ATPS) consists of two immiscible aqueous solutions including two incompatible polymers or one polymer and one salt above a certain critical concentration. The main problems of these polymer-based ATPSs are high viscosity of the polymer and the difficulty to isolate the extracted molecules from the polymer phase by back extraction.

In recent years, ionic liquids (ILs) composed of an organic cation and either an organic or inorganic anion have received more and more attention owing to their special features such as nonvolatility, nonflammability, good solubility, and tunable physical and chemical properties. Some ILs can form ATPSs with concentrated solutions of salts, and these ionic liquid-salt aqueous two-phase systems (ILATPSs) have many advantages, such as low viscosity, gentle biocompatible environment which is much suitable for extraction of bioactive substance, short process time, and high extraction efficiency. Furthermore, proteins [7, 8], amino acids [9], polyphenolic compounds [10], anionic dyes [11], and biomolecules [1214] have been successfully separated and concentrated by the ILATPSs.

Cephalexin (CEX, Figure 1) is hydrosoluble cephalosporins antibiotics. CEX is an amphoteric compound, and its isoelectric point was 4.3 [15]. The conventional methods currently used to extract CEX include liquid-liquid extraction [16], ultrafiltration [17], deproteination by organic solvent [18], solid-phase extraction [19, 20], and liquid membrane extraction [21, 22]. However, these traditional methods increase the total analysis time; using poisonous volatile 


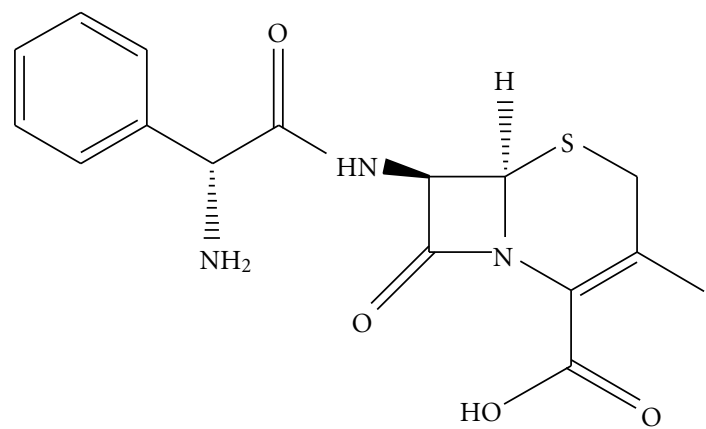

Figure 1: The structure of cephalexin (the isoelectric point, $\mathrm{pI}=4.3)$.

organic solvents or sample recovery is not always satisfactory. ATPE [23, 24], an alternative method, seems to be highly warranted from economic points of view. And in general, PEG-salt ATPS was employed for CEX extraction. Up to now, there have been few reports on using IL-based ATPS to extract CEX. Guo et al. [25] studied the partition of CEX by 1butyl-3-methylimidazolium tetrafluoroborate $\left([\mathrm{Bmim}] \mathrm{BF}_{4}\right)$ $\mathrm{MgSO}_{4}$ ILATPS. In this study, the feasibility of extracting $\mathrm{CEX}$ by $[\mathrm{Bmim}] \mathrm{BF}_{4}-\mathrm{ZnSO}_{4}$ ILATPS was first reported. In an acidic environment, the CEX was easy to be extracted to the [Bmim $] \mathrm{BF}_{4}$-rich phase. In this paper, $\mathrm{ZnSO}_{4}$, an acid salt, was chosen as the phase-separation salt. The factors of the volume of $[\mathrm{Bmim}] \mathrm{BF}_{4}$, the concentration of $\mathrm{ZnSO}_{4}$, temperature, $\mathrm{pH}$, and the volume of $\mathrm{ZnSO}_{4}$ solution affecting the partition of CEX were investigated.

\section{Experimental}

2.1. Reagents and Instruments. $[\mathrm{Bmim}] \mathrm{BF}_{4}$ was purchased from Chengjie Chemical Co., Ltd. (Shanghai, China) with a quoted purity of greater 0.99 mass fraction. $\mathrm{ZnSO}_{4}$ of analytical grade with a minimum mass fraction purity of 99.5\% and methanol of HPLC grade were procured from Sinopharm Chemical Reagent Co., Ltd. (Shanghai, China). The standard sample of cephalexin was obtained from the Chinese National Institute for the Control of Pharmaceutical and Biological Products (Beijing, China). All chemicals were used without further purification. The stock solution of CEX was prepared at a concentration of $1000 \mu \mathrm{g} \cdot \mathrm{mL}^{-1}$ and stored at $4^{\circ} \mathrm{C}$ in a refrigerator. Standard working solutions of CEX were prepared by appropriately diluting the stock solution. All the solutions were prepared using deionized water throughout the entire experiments.

The BS124S electron balance (Beijing Sartorius instrument Co., Ltd., Beijing, China) was used for weighting. The $\mathrm{pH}$ was measured by a digital $\mathrm{pH}$ meter (Shanghai LIDA Instrument Factory, China). The Anke TDL-4 centrifuge (Shanghai, China) was used for centrifuging. The temperature was controlled by a thermostatic water bath (Henan, China). An Agilent 1200 HPLC (Agilent, USA) equipped with a quaternary pump and an ultraviolet-visible (UV) detector was used for analysis of extraction products. The instrument control and data processing were actualized by using Agilent ChemStation software.

2.2. Aqueous Two-Phase Extraction. Aqueous two-phase extraction experiments were implemented by mixing the stock solutions of CEX and $\mathrm{ZnSO}_{4}$ in $10 \mathrm{~mL}$ graduated tubes. The concentrations of $\mathrm{ZnSO}_{4}$ studied were 20 46\%, and the mass of CEX in it was $100 \mu \mathrm{g}$. The $\mathrm{pH}$ of the mixed solutions was adjusted by adding hydrochloric acid and ammonia water into the stock solutions. Then different volumes of $[\mathrm{Bmim}] \mathrm{BF}_{4}(1 \sim 5 \mathrm{~mL})$ were added to the above mixed solutions. After plenarily mixing, the mixture was centrifuged at 2,000 rpm for $15 \mathrm{~min}$ and then placed into a thermostatic water bath at $35 \pm 0.05^{\circ} \mathrm{C}$ for $30 \mathrm{~min}$ to reach thorough phase separation. The volumes of the top and bottom phases were recorded precisely.

The partitions of CEX between the two phases were characterized by extraction efficiency $(E)$ and volume ratio $(R)$. The partitioning parameters were calculated by the following equations:

$$
\begin{gathered}
E=\frac{C_{t} V_{t}}{m_{s}} \times 100 \% \\
R=\frac{V_{t}}{V_{b}},
\end{gathered}
$$

where $C_{t}$ was the equilibrium concentration of CEX in the top phase, $m_{s}$ was the mass of CEX initially added, and $V_{t}$ and $V_{b}$ were the volumes of the top and bottom phases, respectively.

2.3. Analytical Method. After equilibrium was reached, the top phase was directly injected to HPLC without any treatment. An analytical reversed-phase column (Eclipse XDBC18 column, $250 \mathrm{~mm} \times 4.6 \mathrm{~mm}, 5 \mu \mathrm{m}$, serial no. G1314B) was used for chromatographic separations. The ratio of mobile phase of methanol and water was 23:77 at the flow rate of $1.0 \mathrm{~mL} \cdot \mathrm{min}^{-1}$ and the column temperature of $25^{\circ} \mathrm{C}$. The injected volume was $20 \mu \mathrm{L}$ and the column effluent was monitored at a wavelength of $261 \mathrm{~nm}$. The calibration curve for CEX obtained in the range of $0.10 \sim 100 \mu \mathrm{g} \cdot \mathrm{mL}^{-1}$ was $A=$ $26.1428284 \times C-2.4398705(R=0.99999)$, where $C$ was the concentration of CEX $\left(\mu \mathrm{g} \cdot \mathrm{mL}^{-1}\right)$ and $A$ was the peak area.

\section{Results and Discussion}

3.1. Effect of the Volume of $[\mathrm{Bmim}] \mathrm{BF}_{4}$ and the Concentration of $\mathrm{ZnSO}_{4}$. The extraction efficiency of CEX in $[\mathrm{Bmim}] \mathrm{BF}_{4}$ $\mathrm{ZnSO}_{4}$ ILATPS at different volumes of $[\mathrm{Bmim}] \mathrm{BF}_{4}$ and concentrations of $\mathrm{ZnSO}_{4}$ was listed in Figures 2 and 3. In Figure 2, different volumes of [Bmim] $\mathrm{BF}_{4}$ were added to $3 \mathrm{~mL}$ $\mathrm{CEX}$ solutions containing different amount of $\mathrm{ZnSO}_{4}$. When the volume of $[\mathrm{Bmim}] \mathrm{BF}_{4}$ was $1 \mathrm{~mL}$, the minimal concentration of $\mathrm{ZnSO}_{4}$ which can form ATPS was $20 \%$. When the concentration of $\mathrm{ZnSO}_{4}$ was $38 \%$ and the volume of [Bmim] $\mathrm{BF}_{4}$ was higher than $3 \mathrm{~mL}$, or when the concentration of $\mathrm{ZnSO}_{4}$ was $44 \%$ and the volume of [Bmim] $\mathrm{BF}_{4}$ was greater than $2 \mathrm{~mL}$, there was precipitation of $\mathrm{ZnSO}_{4}$ generated. The extraction efficiency of CEX was influenced by the combined 


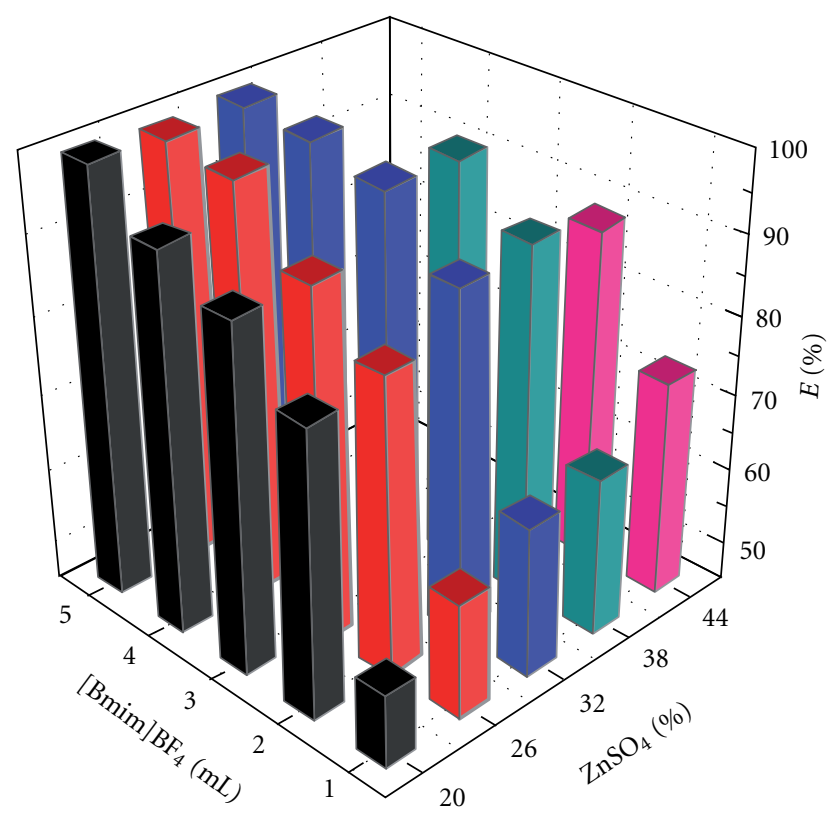

FIGURE 2: The influence of the volume of $\left[\mathrm{Bmim}^{\mathrm{B}}\right] \mathrm{BF}_{4}$ on the extraction efficiency $(E, \%)$ of CEX at different concentrations of $\mathrm{ZnSO}_{4}$.

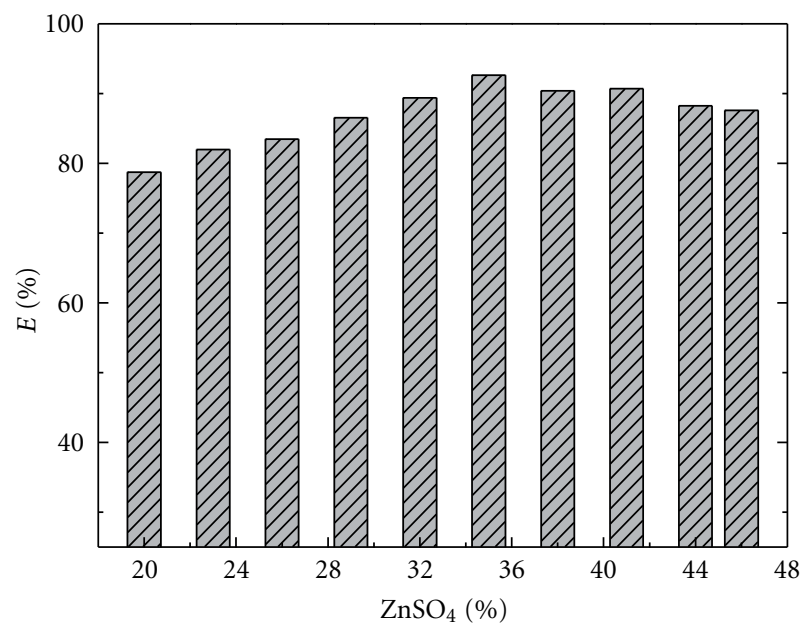

FIgUrE 3: The influence of the concentration of $\mathrm{ZnSO}_{4}$ on the extraction efficiency $(E, \%)$ of CEX.

impacts of the volume of [ $\mathrm{Bmim}] \mathrm{BF}_{4}$ and the concentration of $\mathrm{ZnSO}_{4}$. When the volume of $[\mathrm{Bmim}] \mathrm{BF}_{4}$ was $3 \mathrm{~mL}$ and the concentration of $\mathrm{ZnSO}_{4}$ was $20 \%$, the extraction efficiency of CEX was about $90 \%$; nevertheless, when the volume of [Bmim] $\mathrm{BF}_{4}$ was $2 \mathrm{~mL}$ and the concentration of $\mathrm{ZnSO}_{4}$ was $38 \%$, the extraction efficiency of CEX has already reached $90 \%$.

As shown in Figure 2, when the concentration of $\mathrm{ZnSO}_{4}$ was a fixed value, the extraction efficiency of CEX increased with the volume of $[\mathrm{Bmim}] \mathrm{BF}_{4}$ increasing. The hydration between salt ions and water molecules leads to the phaseforming salt dissolving in the bottom phase; meanwhile, the amount of free water molecules in the bottom phase reduces, and it results in the exclusion of $[\mathrm{Bmim}] \mathrm{BF}_{4}$ and target. The amount of water molecules in the $[\mathrm{Bmim}] \mathrm{BF}_{4}$-rich phase rose with the increase of the volume of $[\mathrm{Bmim}] \mathrm{BF}_{4}$, and due to the good water solubility of CEX, the amount of CEX which can transfer to the top phase also increased.

The impact of salt on the partition of CEX in the [Bmim] $\mathrm{BF}_{4}-\mathrm{ZnSO}_{4}$ ILATPS is largely as a result of the salting-out effect of salt on the liquid-liquid equilibrium of ATPS. For instance, in Figure 2, when the volume of $[\mathrm{Bmim}] \mathrm{BF}_{4}$ was $1 \mathrm{~mL}$, the extraction efficiency of CEX improved with the concentration of $\mathrm{ZnSO}_{4}$ adding. Figure 3 showed the influence of the concentration of $\mathrm{ZnSO}_{4}$ on the extraction efficiency of CEX when the volume of $\left[\mathrm{Bmim}^{\mathrm{B}}\right] \mathrm{BF}_{4}$ was $2 \mathrm{~mL}$. The extraction efficiency of CEX achieved the maximum value (92.64\%) when the concentration of $\mathrm{ZnSO}_{4}$ was $35 \%$. Then with the growth in the concentration of $\mathrm{ZnSO}_{4}$, the extraction efficiency slightly decreased. Similarly, from Figure 2, when the volume of [Bmim] $\mathrm{BF}_{4}$ was $2 \mathrm{~mL}$ or $3 \mathrm{~mL}$, the extraction efficiency of CEX was obviously the same trend. When the salt solution reached equilibrium concentration in the bottom phase, redundant salt will remove to the top phase as salt concentration increased. The salt dissolving in the top phase combined with water molecules through hydration, so the amount of free water molecules in the top phase reduced, leading to a small part of CEX retransferring to the bottom phase. Therefore, high concentration of salt was not conducive to the extraction of the target. From Figures 2 and 3, when the concentration of $\mathrm{ZnSO}_{4}$ was a fixed value and the volume of $[\mathrm{Bmim}] \mathrm{BF}_{4}$ was from $1 \mathrm{~mL}$ to $5 \mathrm{~mL}$, the extraction efficiency of CEX obviously increased, especially when the volume of $\left[\mathrm{Bmim}_{\mathrm{BF}}\right.$ was from $1 \mathrm{~mL}$ to $2 \mathrm{~mL}$. However, when the volume of $[\mathrm{Bmim}] \mathrm{BF}_{4}$ was a fixed value, the growth of extraction efficiency of CEX slowly increased with the increase of salt concentration. So the effect of the volume of $[\mathrm{Bmim}] \mathrm{BF}_{4}$ on the extraction efficiency of CEX was greater than that of the concentration of $\mathrm{ZnSO}_{4}$.

3.2. Effect of Temperature. The influence of temperature on the extraction efficiency of CEX was discussed from $15^{\circ} \mathrm{C}$ to $55^{\circ} \mathrm{C}$ when the volume of $[\mathrm{Bmim}] \mathrm{BF}_{4}$ was $2 \mathrm{~mL}$ and the concentration of $\mathrm{ZnSO}_{4}$ was 35\%. After equilibrium reached, the changes of the volume of the top phase and the extraction efficiency of CEX were described in Figure 4. The extraction efficiency of CEX increased in the range of $15 \sim 35^{\circ} \mathrm{C}$. The volumes of the $[\mathrm{Bmim}] \mathrm{BF}_{4}$-rich phase always enlarged as the temperature rose, and it means that more and more water molecules were transferred to the top phase. Therefore, the extraction efficiency of CEX should have increased from $15^{\circ} \mathrm{C}$ to $55^{\circ} \mathrm{C}$. But at the temperature of $45^{\circ} \mathrm{C}$, the extraction efficiency began to decline. This was because the CEX was unstable at relatively high temperature. At $55^{\circ} \mathrm{C}$, more $\mathrm{CEX}$ was decomposed, and the extraction efficiency of CEX decreased to $64 \%$. It can be seen that the temperature is an essential factor affecting the partition of $\mathrm{CEX}$ in $[\mathrm{Bmim}] \mathrm{BF}_{4}-\mathrm{ZnSO}_{4}$ ILATPS.

3.3. Effect of the Volume of $\mathrm{ZnSO}_{4}$ Solution. At the $\mathrm{pH}$ without adjusting, the influence of the volume of $\mathrm{ZnSO}_{4}$ 


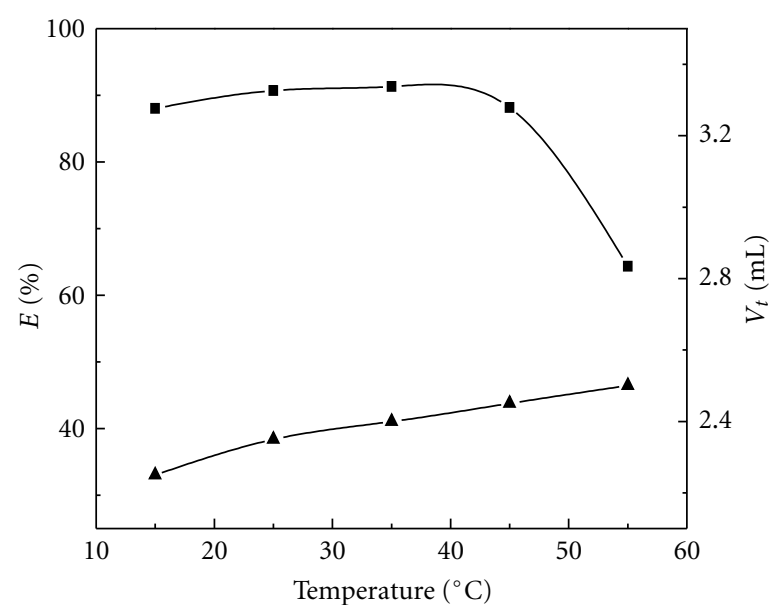

FIGURE 4: The influence of temperature on the extraction efficiency $(E, \%)$ of CEX and the volume of the top phase $\left(V_{t}\right): \mathbf{\square}, E(\%) ; \boldsymbol{\Delta}, V_{t}$ $(\mathrm{mL})$.

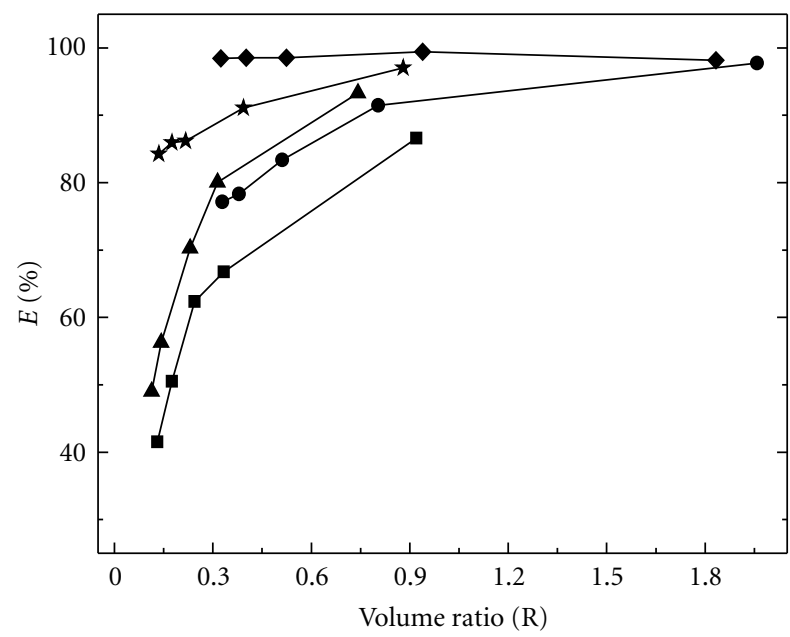

Figure 5: The influence of $\mathrm{pH}$ and the volume of $\mathrm{ZnSO}_{4}$ solution on the extraction efficiency $(E, \%)$ of CEX: square, $1 \mathrm{~mL}[\mathrm{Bmim}] \mathrm{BF}_{4}+35 \% \mathrm{ZnSO}_{4} ;$ circle, $2 \mathrm{~mL}[\mathrm{Bmim}] \mathrm{BF}_{4}+35 \%$ $\mathrm{ZnSO}_{4}$; triangle, $1 \mathrm{~mL}[\mathrm{Bmim}] \mathrm{BF}_{4}+46 \% \mathrm{ZnSO}_{4}$; star, $\mathrm{pH}=1$, $1 \mathrm{~mL}\left[\mathrm{Bmim}^{\mathrm{B}}\right] \mathrm{BF}_{4}+35 \% \quad \mathrm{ZnSO}_{4} ;$ diamond, $\mathrm{pH}=1, \quad 2 \mathrm{~mL}$ $[\mathrm{Bmim}] \mathrm{BF}_{4}+35 \% \mathrm{ZnSO}_{4}$.

solution on the extraction efficiency of CEX was discussed. There were three ILATPSs, respectively, forming by different volumes of $\mathrm{ZnSO}_{4}$ solution in the same $\mathrm{ZnSO}_{4}$ concentration with the same volume of $\left[\mathrm{Bmim}_{\mathrm{BF}_{4}}\right.$. In detail, the three ILATPSs were composed of $35 \% \mathrm{ZnSO}_{4}+1 \mathrm{~mL}[\mathrm{Bmim}] \mathrm{BF}_{4}$, $35 \% \mathrm{ZnSO}_{4}+2 \mathrm{~mL}[\mathrm{Bmim}] \mathrm{BF}_{4}$, and $46 \% \mathrm{ZnSO}_{4}+1 \mathrm{~mL}$ [Bmim] $\mathrm{BF}_{4}$ with $100 \mu \mathrm{g}$ CEX, respectively. From Figure 5, with the volume of the bottom phase (salt-rich phase) reducing, which also means the volume ratio increasing, the extraction efficiency of CEX always increased in the three ILATPSs. For example, when the volume of $\left[\mathrm{Bmim}^{\mathrm{B}} \mathrm{BF}_{4}\right.$ was $1 \mathrm{~mL}$ and the concentration of $\mathrm{ZnSO}_{4}$ was $35 \%$, different volumes of $\mathrm{ZnSO}_{4}$ solution with $100 \mu \mathrm{g}$ CEX formed ATPSs by adding $[\mathrm{Bmim}] \mathrm{BF}_{4}$. The larger the volume of the bottom phase is, the more water molecules it can get. Then CEX was more inclined to dissolve in the $\mathrm{ZnSO}_{4}$-rich phase, and the extraction efficiency decreased.

3.4. Effect of $p H$. Cephalexin is an amphoteric compound possessing amino group and carboxyl group. The ionization states of CEX molecules vary with $\mathrm{pH}$ in the aqueous solution $[26,27]$. It is positively charged below its isoelectric point of 4.3 and negatively charged above $\mathrm{pH} 4.3$ [15]. The $\mathrm{pH}$ of $\mathrm{ZnSO}_{4}$ solutions is around 3.0. In this experiment, the $\mathrm{pH}$ from 1.0 to 5.0 was investigated. When the $\mathrm{pH}$ was adjusted to 6.0, there was sediment emerging in the bottom phase. The results showed that the extraction efficiency of CEX decreased from $99.31 \%$ to $91.22 \%$ at $\mathrm{pH} 1.0 \sim 4.0$; then it immediately declined to $17.48 \%$ at $\mathrm{pH} 5.0$. At $\mathrm{pH}$ values below 2.6, the predominant form of CEX was cationic. The interaction between the CEX cationic and $\mathrm{H}^{+}$in the bottom phase was the mainly driving force for extraction. At $\mathrm{pH}<$ 2.6, almost all of the CEX was extracted to the top phase. Then with the $\mathrm{pH}$ rising, the extraction efficiency slightly descended. At pH 5.0 which is higher than the isoelectric point of CEX, it is negatively charged. And then it was more inclined to remain in the $\mathrm{ZnSO}_{4}$-rich phase. In Figure 5, when the volume of $\left[\mathrm{Bmim}_{\mathrm{B}} \mathrm{BF}_{4}\right.$ was $1 \mathrm{~mL}$, the extraction efficiency of CEX increased with the volume of $\mathrm{ZnSO}_{4}$ solution decreasing at $\mathrm{pH}$ 1.0. In comparison with the same ATPSs of unadjusted $\mathrm{pH}$, the extraction efficiency of CEX at $\mathrm{pH} 1.0$ was much higher when the volume ratio was similar. When the volume of $[\mathrm{Bmim}] \mathrm{BF}_{4}$ was $2 \mathrm{~mL}$, the extraction efficiency had little difference which was all greater than $98 \%$ at $\mathrm{pH}$ 1.0. So the lower the $\mathrm{pH}$ is, the higher extraction efficiency the CEX has.

\section{Conclusions}

In this paper, the $[\mathrm{Bmim}] \mathrm{BF}_{4}-\mathrm{ZnSO}_{4}$ ILATPS was applied to separate hydrosoluble antibiotics and the partitioning behavior was discussed at great length. The distribution of CEX in the ILATPS was influenced by the volume of [Bmim] $\mathrm{BF}_{4}$, the concentration of $\mathrm{ZnSO}_{4}$, temperature, $\mathrm{pH}$, and the volume of $\mathrm{ZnSO}_{4}$ solution. Without $\mathrm{pH}$ adjusted, the impact of $[\mathrm{Bmim}] \mathrm{BF}_{4}$ and $\mathrm{ZnSO}_{4}$ on the extraction efficiency of CEX was as follows: the volume of $[\mathrm{Bmim}] \mathrm{BF}_{4}>$ the concentration of $\mathrm{ZnSO}_{4}$. CEX was preferentially extracted to the $[\mathrm{Bmim}] \mathrm{BF}_{4}$-rich phase at the $\mathrm{pH}$ below its isoelectric point of 4.3. At $\mathrm{pH} 1.0$, the extraction efficiency of CEX increased with the increase of the volume of $[\mathrm{Bmim}] \mathrm{BF}_{4}$ and the decrease of the volume of $\mathrm{ZnSO}_{4}$ solution; however, the extraction efficiency had little difference at different volumes of $\mathrm{ZnSO}_{4}$ solution when the volume of $[\mathrm{Bmim}] \mathrm{BF}_{4}$ was $2 \mathrm{~mL}$.

\section{Acknowledgments}

This work was supported by the National Natural Science Foundation of China (nos. 21076098, 21206059, and 21207051), the Natural Science Foundation of Jiangsu Province (no. BK2010349 and BK2011529), China Postdoctoral Science Foundation funded Project (no. 20110491352), 
and Jiangsu Postdoctoral Science Foundation funded Project (no. 1101036C).

\section{References}

[1] S. L. Mistry, A. Kaul, J. C. Merchuk, and J. A. Asenjo, "Mathematical modelling and computer simulation of aqueous twophase continuous protein extraction," Journal of Chromatography A, vol. 741, no. 2, pp. 151-163, 1996.

[2] T. W. Tan, Q. Huo, and Q. Ling, "Purification of glycyrrhizin from Glycyrrhiza uralensis Fisch with ethanol/phosphate aqueous two phase system," Biotechnology Letters, vol. 24, no. 17, pp. 1417-1420, 2002.

[3] X. Y. Zhao, F. Qu, M. Dong, F. Chen, A. Q. Luo, and J. H. Zhang, "Separation of proteins by aqueous two-phase extraction system combined with liquid chromatography," Chinese Journal of Analytical Chemistry, vol. 40, no. 1, pp. 38-42, 2012.

[4] T. Karkaşand and S. Önal, "Characteristics of invertase partitioned in poly(ethylene glycol)/magnesium sulfate aqueous two-phase system," Biochemical Engineering Journal, vol. 60, pp. 142-150, 2012.

[5] P. A. J. Rosa, A. M. Azevedo, I. F. Ferreira, S. Sommerfeld, W. Bäcker, and M. R. Aires-Barros, "Downstream processing of antibodies: single-stage versus multi-stage aqueous two-phase extraction," Journal of Chromatography A, vol. 1216, no. 50, pp. 8741-8749, 2009.

[6] B. Mokhtarani, R. Karimzadeh, M. H. Amini, and S. D. Manesh, "Partitioning of Ciprofloxacin in aqueous two-phase system of poly(ethylene glycol) and sodium sulphate," Biochemical Engineering Journal, vol. 38, no. 2, pp. 241-247, 2008.

[7] C. Y. He, S. H. Li, H. W. Liu, K. A. Li, and F. Liu, "Extraction of testosterone and epitestosterone in human urine using aqueous two-phase systems of ionic liquid and salt," Journal of Chromatography A, vol. 1082, no. 2, pp. 143-149, 2005.

[8] Z. J. Tan, F. F. Li, X. L. Xu, and J. M. Xing, "Simultaneous extraction and purification of aloe polysaccharides and proteins using ionic liquid based aqueous two-phase system coupled with dialysis membrane," Desalination, vol. 286, pp. 389-393, 2012.

[9] Y. C. Pei, Z. Y. Li, L. Liu, and J. J. Wang, "Partitioning behavior of amino acids in aqueous two-phase systems formed by imidazolium ionic liquid and dipotassium hydrogen phosphate," Journal of Chromatography A, vol. 1231, pp. 2-7, 2012.

[10] F. Y. Du, X. H. Xiao, X. J. Luo, and G. K. Li, "Application of ionic liquids in the microwave-assisted extraction of polyphenolic compounds from medicinal plants," Talanta, vol. 78, no. 3, pp. 1177-1184, 2009.

[11] Y. C. Pei, J. J. Wang, X. P. Xuan, J. Fan, and M. H. Fan, "Factors affecting ionic liquids based removal of anionic dyes from water," Environmental Science and Technology, vol. 41, no. 14, pp. 5090-5095, 2007.

[12] J. F. B. Pereira, Á. S. Lima, M. G. Freire, and J. A. P. Coutinho, "Ionic liquids as adjuvants for the tailored extraction of biomolecules in aqueous biphasic systems," Green Chemistry, vol. 12, no. 9, pp. 1661-1669, 2010.

[13] C. L. S. Louros, A. F. M. Cláudio, C. M. S. S. Neves et al., "Extraction of biomolecules using phosphonium-based ionic liquids $+\mathrm{K}_{3} \mathrm{PO}_{4}$ aqueous biphasic systems," International Journal of Molecular Sciences, vol. 11, no. 4, pp. 1777-1791, 2010.

[14] M. Domínguez-Pérez, L. I. N. Tomé, M. G. Freire, I. M. Marrucho, O. Cabeza, and J. A. P. Coutinho, "(Extraction of biomolecules using) aqueous biphasic systems formed by ionic liquids and aminoacids," Separation and Purification Technology, vol. 72, no. 1, pp. 85-91, 2010.

[15] W. E. Gager, F. J. Elsas, and J. L. Smith, "Ocular penetration of cephalexin in the rabbit," British Journal of Ophthalmology, vol. 53, no. 6, pp. 403-406, 1969.

[16] J. B. Lecaillon, M. C. Rouan, and C. Souppart, "Determination of cefsulodin, cefotiam, cephalexin, cefotaxime, desacetylcefotaxime, cefuroxime and cefroxadin in plasma and urine by high-performance liquid chromatography," Journal of Chromatography, vol. 228, pp. 257-267, 1982.

[17] J. Keever, R. D. Voyksner, and K. L. Tyczkowska, “Quantitative determination of ceftiofur in milk by liquid chromatographyelectrospray mass spectrometry," Journal of Chromatography A, vol. 794, no. 1-2, pp. 57-62, 1998.

[18] W. A. Moats and R. D. Romanowski, "Multiresidue determination of $\beta$-lactam antibiotics in milk and tissues with the aid of high-performance liquid chromatographic fractionation for clean up," Journal of Chromatography A, vol. 812, no. 1-2, pp. 237-247, 1998.

[19] C. Quesada-Molina, B. Claude, A. M. García-Campaña, M. del Olmo-Iruela, and P. Morin, "Convenient solid phase extraction of cephalosporins in milk using a molecularly imprinted polymer," Food Chemistry, vol. 135, pp. 775-779, 2012.

[20] S. G. Wu, E. P. C. Lai, and P. M. Mayer, "Molecularly imprinted solid phase extraction-pulsed elution-mass spectrometry for determination of cephalexin and $\alpha$-aminocephalosporin antibiotics in human serum," Journal of Pharmaceutical and Biomedical Analysis, vol. 36, no. 3, pp. 483-490, 2004.

[21] M. E. Vilt and W. S. W. Ho, "In situ removal of Cephalexin by supported liquid membrane with strip dispersion," Journal of Membrane Science, vol. 367, no. 1-2, pp. 71-77, 2011.

[22] G. C. Sahoo and N. N. Dutta, "Studies on emulsion liquid membrane extraction of cephalexin," Journal of Membrane Science, vol. 145, no. 1, pp. 15-26, 1998.

[23] M. M. Bora, S. Borthakur, P. C. Rao, and N. N. Dutta, "Aqueous two-phase partitioning of cephalosporin antibiotics: effect of solute chemical nature," Separation and Purification Technology, vol. 45, no. 2, pp. 153-156, 2005.

[24] J. H. Zhu, D. Z. Wei, X. J. Cao, Y. Q. Liu, and Z. Y. Yuan, "Partitioning behaviour of cephalexin and 7-aminodeacetoxicephalosporanic acid in PEG/ammonium sulfate aqueous two-phase systems," Journal of Chemical Technology and Biotechnology, vol. 76, no. 11, pp. 1194-1200, 2001.

[25] X. Guo, X. R. Yu, S. K. Li, X. Z. Zhang, Y. H. Shen, and Y. Wang, "Microwave assisted synthesis of [Bmim]BF4and application in the extraction of cefalexin," Chemical Research and Application, vol. 22, pp. 1505-1509, 2010.

[26] K. Y. Wang and T. S. Chung, "The characterization of flat composite nanofiltration membranes and their applications in the separation of Cephalexin," Journal of Membrane Science, vol. 247, no. 1-2, pp. 37-50, 2005.

[27] G. C. Sahoo, A. C. Ghosh, and N. N. Dutta, "Recovery of cephalexin from dilute solution in a bulk liquid membrane," Process Biochemistry, vol. 32, no. 4, pp. 265-272, 1997. 

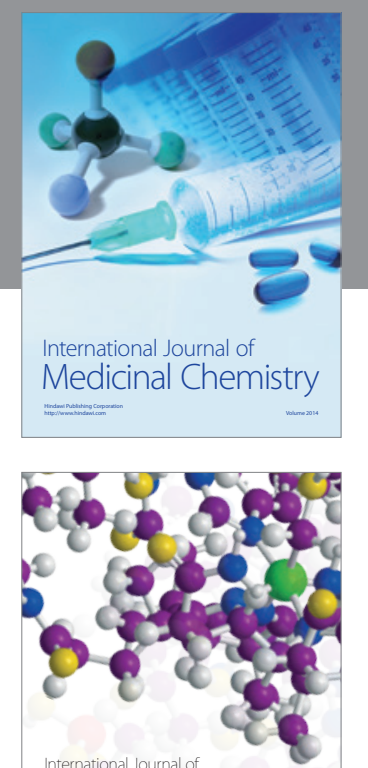

\section{Carbohydrate} Chemistry

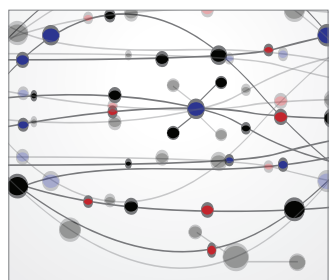

The Scientific World Journal
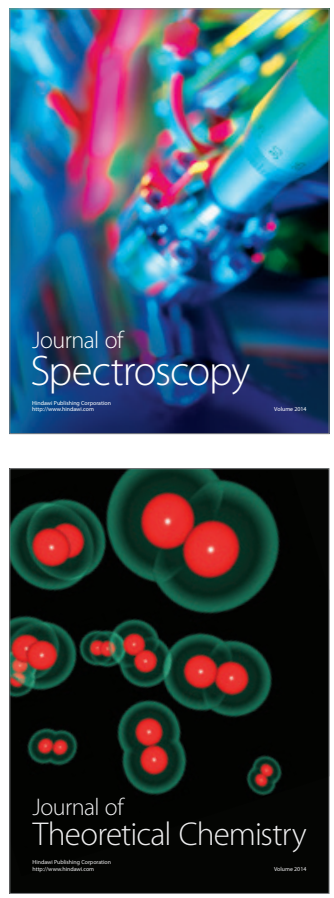
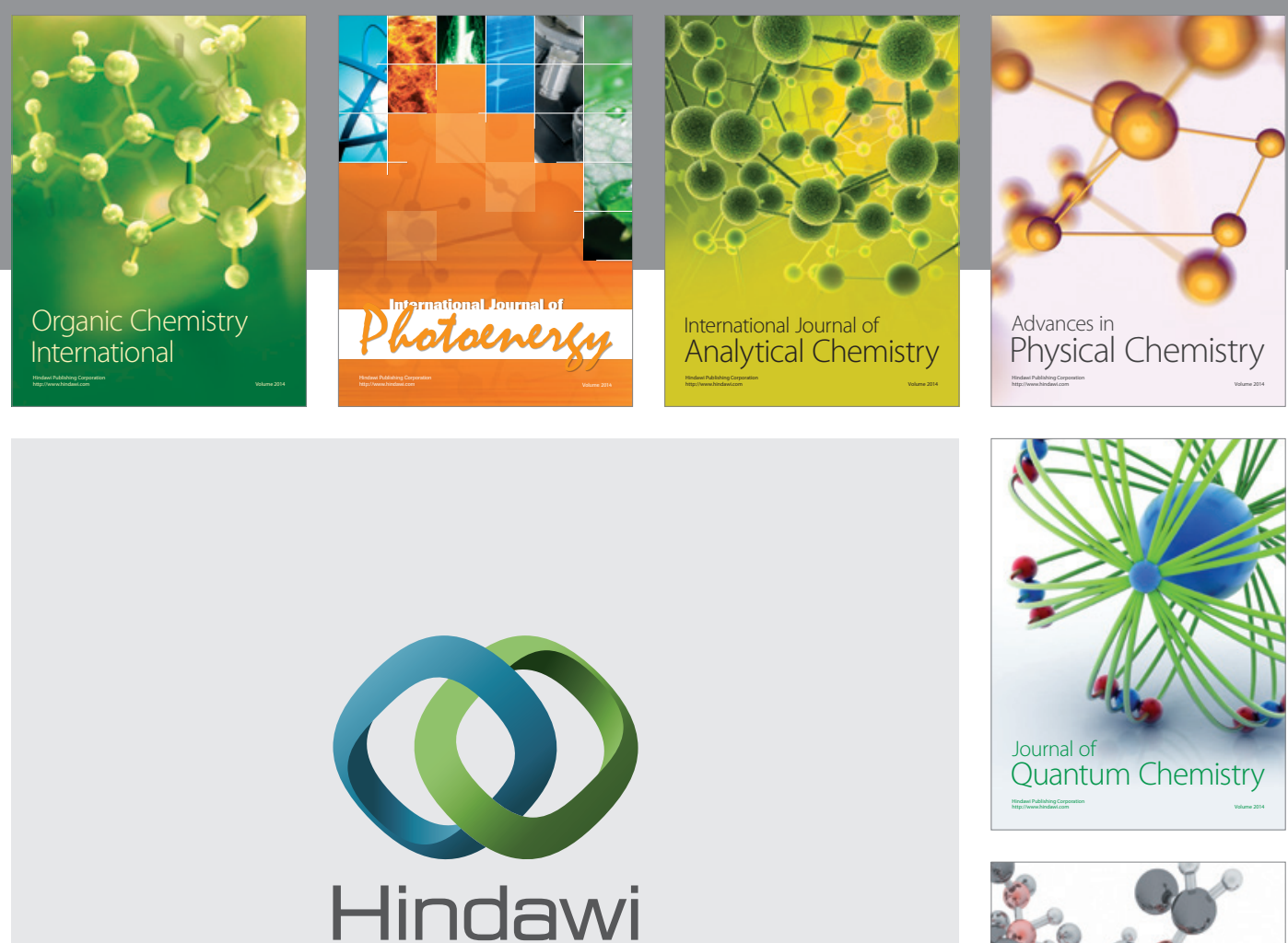

Submit your manuscripts at

http://www.hindawi.com

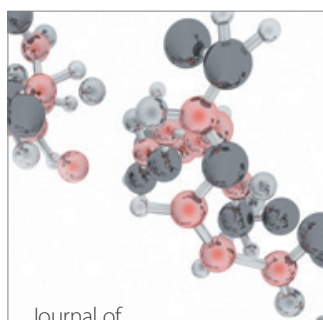

Analytical Methods

in Chemistry

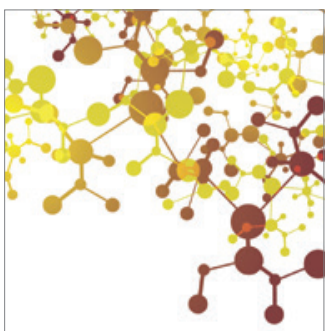

Journal of

Applied Chemistry

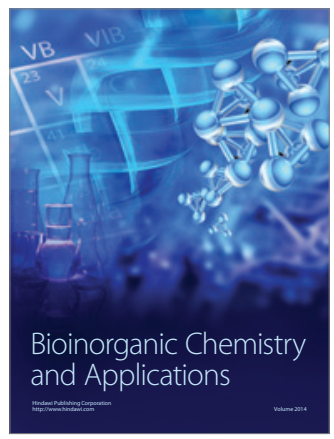

Inorganic Chemistry
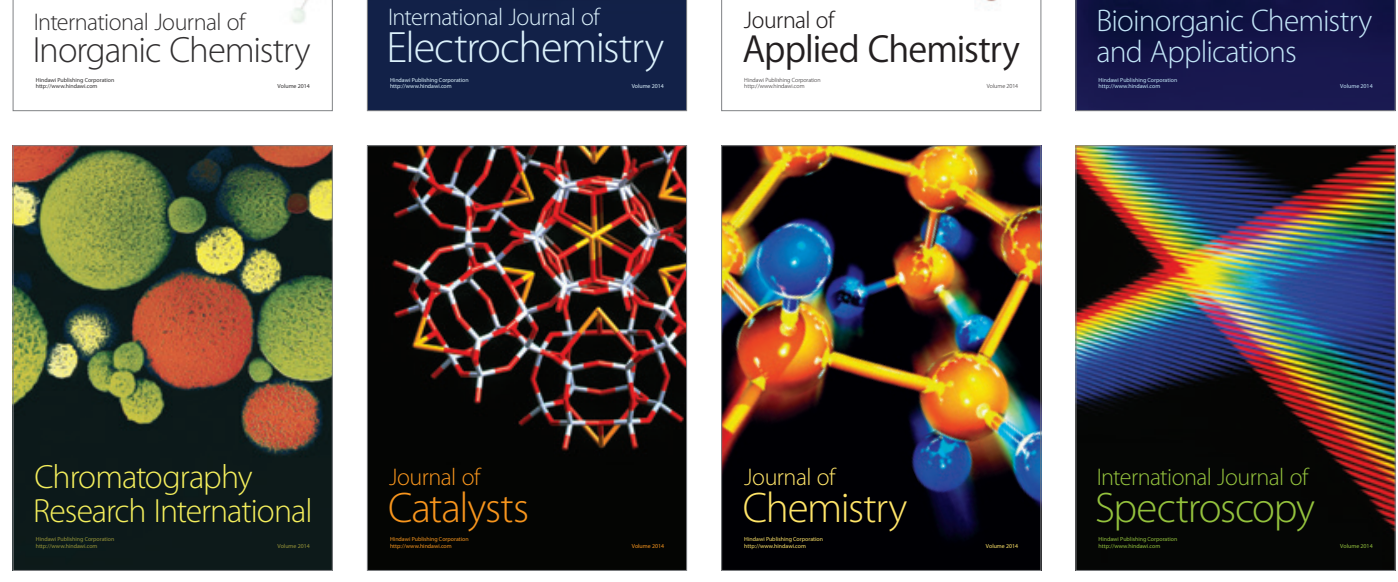